\title{
Struggles for Electrical Power Supply in Sudan and South Sudan
}

\author{
Dina Ahmed Mohamed Ghandour
}

Abstract:

\begin{abstract}
Adequate power supply is an unavoidable requirement to any nation's development. Industrialization and modernization cannot be achieved without proper access to electricity. Sudan and South Sudan electrical power sector is facing a lot of struggles and challenges, with Sudan's electrical power sector is subject to poor infrastructure, frequent power cut off and faces other sort of challenges. On the other hand, South Sudan has a very hard situation as only $1 \%$ of South Sudan population has access to electricity.
\end{abstract}

The purpose of this paper is to investigate and focus on the different electrical power struggles faced by Sudan and South Sudan nations, and the main reasons of them, as well as, it has presented the different proposed developmental plans set for improving electrical power supply in the future. Moreover, it has provided a comparison between the two countries and country-world comparison in terms of the electrical power sector. This paper followed the analytical/qualitative method to investigate such a problem. Semi-structured interviews were used as the main data collection tool, and secondary data was also collected. The collected data was analyzed based on the problem statement, and hypothesis derived from the theoretical framework.

Key words:

Electrical power Supply, electrical power sector, Sudan, South Sudan, Developments and Struggles.

Introduction:

The discovery of electricity is one of the greatest achievements. It helped to remove darkness and increase human activity. Powerful lights are used in factories, schools, hospitals and in all other dark places where men have to work for the benefit of others or for themselves.

Electricity has also enabled people to increase the production of their goods. Huge machines are operated in large factories with the help of electricity for the manufacture of useful goods. These machines work ceaselessly and produce enormous quantities of goods, which are distributed throughout the world, for the comfort of people in all parts of the earth.

Even to transport goods and people to the remotest regions of the earth, electricity is extremely useful. Land, air and sea transport are all assisted by the use of electricity. People can now travel in great comfort and ease for business or pleasure to any part of the world. In the same way, goods can be sent to all the corners of the earth with the greatest of ease.

Electricity is even used for the treatment of some people who suffer from abnormal diseases. In short, the use of electricity has changed the lives of people in a way that life without it is almost unthinkable. This paper will explore the struggles of electricity supply in Sudan and South Sudan.

Dina Ahmed Mohamed Ghandour

Faculty of Business Administration/University of Medical Sciences and Technology, Khartoum/Sudan
Sudan and South Sudan- an overview:

Sudan and South Sudan, both located in northeastern Africa, became independent countries in 9 July 2011, following a referendum in South Sudan where the people overwhelmingly voted for independence. Prior to the split, the unified Sudan was the second-largest oil producer in Africa in 2010, outside of the Organization of the Petroleum Exporting Countries (OPEC). Since the split, Sudan and South Sudan's production has declined, and together they ranked as the fourth-largest non-OPEC African oil producer in 2013. Disagreements over oil revenue sharing and armed conflict have reduced oil production from both countries over the past few years.

Sudan and South Sudan's oil sectors are still closely linked. Because South Sudan is landlocked, it remains dependent on Sudan to transport its oil through Sudan's pipelines to the Bashayer port along the Red Sea. Southern Sudan is divided in 10 states with only 3 of the state capitals (Juba, Malakal and Wau) having decentralized generation with localized distribution network. It is rich in resource potential such as hydro, solar and biomass, but severely impacted by the effects of a civil war.

Background of Electrical power sector in Sudan and South Sudan:

Sudan's electrical power sector has been subject to poor infrastructure and experiences frequent power outages. At present the country's electricity generating capacity consists of about 760 megawatts of thermal power, about 320 megawatts of hydropower capacity, and total electricity generation is 3.2 billion kilowatt hours (Bow). About $70 \%$ of the electricity is consumed in the Khartoum area. Rural areas are without access to electricity, except for some large, export-oriented agricultural schemes.

Electrical power is transmitted through two interconnected electrical grids, the Blue Nile Grid and the Western grid, which encompasses a small portion of the country. Regions in Sudan that are not covered by the grid rely on small diesel-fired generators for power. Only 30 percent of Sudan's population currently has access to electricity, the government hopes to increase that figure to 90 percent in the near future. Civil war in the country has curtailed foreign investment in the Sudanese power sector, but it is expected to increase with the cessation of the civil conflict. In June 2004 the United Arab Emirates (UAE) pledged to invest in the Sudanese power sector following the signing of a peace accord. In January 2006, the Export/Import Bank of India extended $\$ 350$ million of credit to the country for the construction of a 500-MW power plant.

Sudan's power utility is the state-owned National Electricity Corporation of Sudan (NEC). Two electric power stations have been inaugurated in June 2004 and they are estimated to have a combined capacity of $330 \mathrm{MW}$, two facilities that would participate in the supply of power, The El Jaili Power project is a power plant that has been constructed by the National NEC in the vicinity of Khartoum, El-Jaili combined cycle power station also 
known as Plant 1 . The Dit Kilo $\mathrm{X}$ power station is powered by diesel and has a working capacity of a $257 \mathrm{MW}$. The project consisted of 7 diesel units that were interconnected at the existing Kilo X substation where bays for injection of $110 \mathrm{KV}$ have been made available. It was Sudan's first Independent Power Production (IPP) project that was completed in 2004. There also exist the 300-MW Kajbar hydroelectric facilities in northern Sudan.

Moreover, the Chinese funded $\mathrm{f} 1.2$ billion to construct $174 \mathrm{~km}$ Merowe Dam which is situated on the River Nile and its construction finished in 2009. As a result, the construction of such a dam doubled the country's power generation at the time. Furthermore, one of the biggest development projects that hit Sudan is the Roseires Dam on the Blue Nile in the south of the country (this time by Gulf donors), boosting not only the existing dam's power supply, but also further downstream in the Merowe plant, as well as improving irrigation and agricultural productivity in the area.

In 2010, Sudan government decided to establish a separate Ministry of electricity and to restructure the previous National Electricity Corporation of Sudan (NEC) in to five state holding Companies, which are demonstrated in figure 1 below, the direct supervision of these five companies went to the Ministry;

\section{Figure 1: Structure of the Electricity Sector}

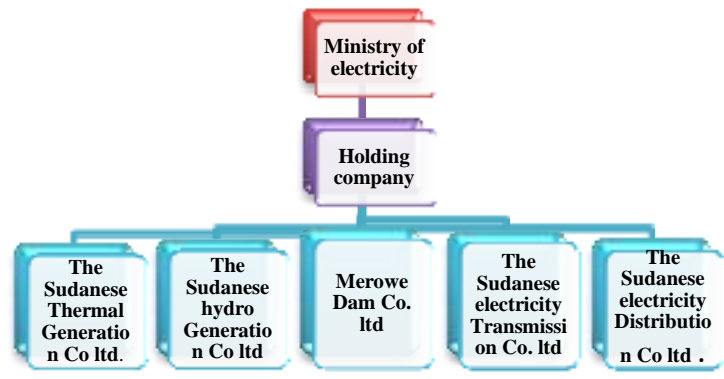

On the other hand, until the recent past, in South Sudan the energy sector was the responsibility of the Ministry of Energy and Mines (MEM). Following independence, a restructuring of the public institutions was implemented; as a result, MEM was divided into two ministries, namely, Ministry of Electricity and Dam (MOED) and Ministry of Petroleum and Mining (MOPM). The other main players in the energy sector are South Sudan Electricity Corporation (SSEC) and Nile Petroleum Corporation (Nilepet) dealing with electricity and oil, respectively. The former reports to MOED while the latter reports to MOPM. It is expected that an Electricity Regulatory Agency and Petroleum Regulatory Agency will be established following the enactment of the respective Bill. The institution structure for the ESI (Electricity Supply Industry) is provided in Figure 2 below.
Figure 2: Institution Structure of the Electricity Sector

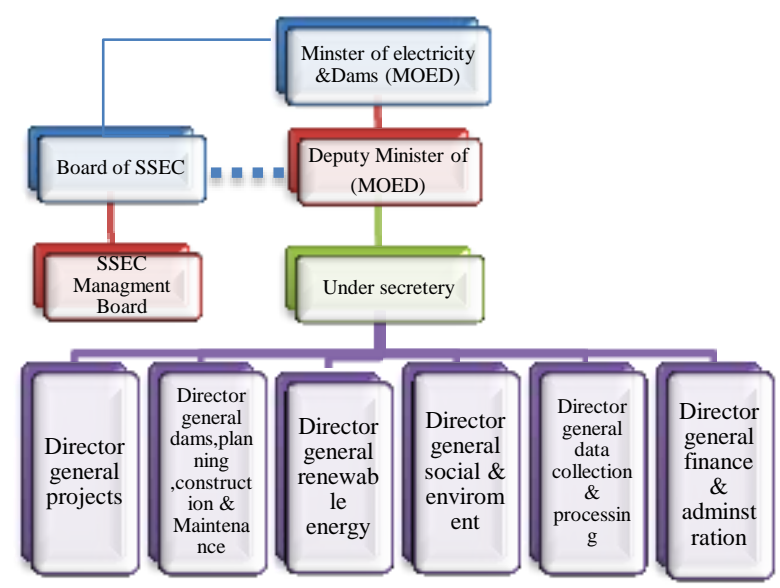

Source: Ministry of Electricity and Dams.

However, beside all this changes and developments in the electrical power sector in Sudan and South Sudan, but supply still there are a lot of struggles facing authorities to effectively electricity in both countries.

\section{Theoretical Framework:}

\section{Problem Statement:}

Sudan's electrical power sector which has been subject to poor infrastructure, frequent power cut off, have experiences frequent power outages in many parts of the country during the last quarter of 2015 , creating a sense of complaints among citizens who were affected by the interruption of electricity Supply. As long as the government has noticed in the media that within 2016, it will lift support (increase the price of electricity) from electrical power sector taking in to account the wealthy people as their main target. Moreover, many poor and limited income people considered this step as a red line.

On the other hand, South Sudan is facing challenges to build a strong economy. Industrialization and modernization cannot be achieved without proper access to electricity. Electricity is supplied through diesel powered generators and yet, more than $90 \%$ of the South Sudanese people are without access to electricity, with an estimated only $1 \%$ of the 11 million population connected to the nation's electricity power grid and most of those are in the capital, Juba .

\section{Significance of the study:}

This research is conducted in order to; assess the electrical power sector in Sudan and South Sudan, Spotlight on the different Struggles faced by citizens in both countries, explore the necessary solutions needed to avoid all the struggles, present developmental plans set by the authorities, Identify Sudan and South Sudan position in comparison to the world in terms of electricity production and consumption, Moreover there is few researches done in this area. 


\section{Objectives of the study:}

The general objective of the study is to identify the Struggles and developments for electrical power sector in Sudan and South Sudan.

More specifically, to investigate how the decision of lift support from electrical power sector which was set by the government will affect the poor, and low income people in Sudan. Also it will highlights the framework document which was set for promoting the electrical sector in the upcoming period 2015-2020, as well as South Sudan infrastructure action plan which was set for supporting the electrical sector there for maintaining economic growth.

\section{Hypothesis:}

- South Sudan will build a strong economy and achieve modernization and industrialization, if they strength their electrical power sector and there were sufficient supply to electricity and proper access by citizens.

- Sudan's electrical power sector will be free from frequent power cut off and a lot of complains by citizens, if government aspires to increase electricity production in the country.

- Poor and limited income people demands for electricity will be effectively met, if government took them in to account when deciding to raise the prices of electricity in the country.

\section{Methodology}

The research is based on analytical and qualitative methods.

\section{Target Population}

The targeted population of the study is the suppliers of electricity in both countries, mainly the authorities in the Ministry of Electricity.

\section{Data Collection}

Two types of data sources will be integrated; secondary data and primary data. Secondary data is used to gain initial insight into the research problem, it is required in the preliminary stages of research to determine what is known already and what new data is required. Primary data is data that did not exist before. It is designed to answer specific questions of interest of the researcher.

\section{Secondary Data}

Secondary data was obtained from the internet, newspapers and journals on data concerning the two countries.

\section{Primary Data}

Interview was used to collect primary data with the aid of the secondary Source. Semi structured interview with open ended questions are conducted with the regulatory authorities of the Ministry of electricity in both counties.

\section{Sampling method and analysis:}

Purposive sampling method was used "it's a non-probability sampling that selects respondents based on particular knowledge already held about a certain population, and attempts to ensure that "certain types of individuals or persons displaying certain attributes are included in the study." (Berg 1989, 179).
The collected data was analyzed based on the problem statement, and hypothesis derived from the theoretical framework. As well as the research relied on the judgment criteria supplemented by comparing Sudan \& south Sudan electrical power sector with each other's and different countries.

\section{Discussion:}

This paper will spotlight on the electrical power sector for Sudan and South Sudan by discussing the following points:

- Struggles for electrical power supply in both countries

- Developmental plans set for improving the electrical power sector in Sudan \& South Sudan. As well as it will mention the position of both countries in comparison to the world in terms of electricity production, consumption, supply ....etc.

\section{Struggles for electrical power Supply in Sudan:}

Recently, Sudan government shocked its citizens by announcing its intention to increase the electricity and water consumption tariffs by $100 \%$ in order to ensure stability of electricity and water supplies services. As a result of such a decision Sudan's minister of water resources and electricity, Muataz Musa, has stressed that increase in the price of electricity is inevitable.

Sudan has $40 \%$ electricity shortage and lately in 2015 the capital Khartoum has been plagued with power outages which have also exacerbated water cuts. The minister mentioned that the projected increase in the price of electricity would be approved after conducting wide consultations with the customers, pointing to the need for increasing the price particularly for the rich segments of society.

"[Price increase] is inevitable but low-income people must be taken into consideration", he said. He wondered whether clients need sustainable electricity supply or cheap but unstable supply, emphasizing that limited and middle-income segments of society wouldn't be negatively affected by price changes.

"On what moral and legal bases does the government subsidizes rich people?" he wondered.

Also he mentioned that, current tariff covers only $20 \%$ of the actual operating costs, stressing that low-income wouldn't be affected by the anticipated price increase. The minister said the increase in the tariff is aimed at reducing large consumption during the peak hours which costs the government hundreds of millions of pounds. For this reasons he called on citizens to rationalize consumption, saying they suffer from the intensity of electricity use during the peak hours.

On the other hand, he attributed that the recent electricity cuts was due to different reasons which include:

- The low-level of water in the Meroe dam's lake

- The large increase in the costs of operating the thermal power plants due to high fuel prices. As it cost $\$ 1.5$ billion and consumes between $\$ 500$ to $\$ 600$ million in fuel besides the spare parts.

The minister stressed that the thermal power plant in Port Sudan would add 1500 megawatts to the national grid during the 
upcoming period, emphasizing that electricity supply would stabilize. $\mathrm{He}$ also pointed to the import of solar-powered water pumps for agricultural irrigation, as it's very costly to build solar cells in Sudan. Also he mentioned that ministry's 2016 plan doesn't include programmed electricity cuts, pointing to the anticipated increase in the thermal generation output.

\section{5-2020 framework document for promoting the electricity sector in Sudan:}

The technical committee for the economic development sector, has approved the 2015-2020 framework document for promoting the electricity sector.

The document, aims to raise the annual production capacity of the Hydroelectric generation from 1500 to 2000 Gigawatts / Hour, and the thermoelectric power generation would increase from 900 to 4,555 Megawatts by the end of 2020 . The document also seeks to include all major towns in the war-torn states of Darfur, South Kordofan and the Blue Nile in the national electricity grid.

The Sudanese Electricity Transmission Company (SETCO) signed a \$50 million contract with the Chinese, Shanghai Electric Group Company to link the power line in Darfur to the national electricity grid. The document further aims to reduce the total electric power transmission and distribution losses to \%15 besides localizing the manufacturing of the electrical equipment's.

Moreover, the technical committee for the economic development has recommended the provision of the necessary funding to complete the existing electricity projects and the future plans.

\section{Struggles for electrical power supply in South Sudan:}

A report of South Sudan humanitarian and development statistics which was issued lately by the United Nations showed that only around $1 \%$ of the 11 million population has access to electricity and most of these are in Juba.

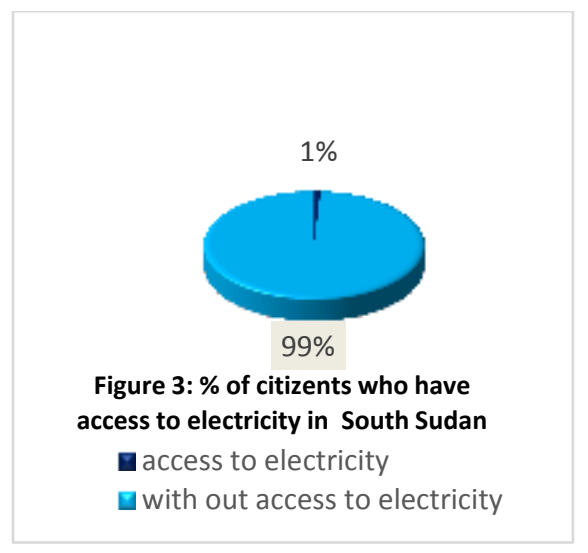

Reasons for limited access to electricity in South Sudan: As a result of civil war in South Sudan, electricity supply is characterized with poor infrastructures, frequent power breaks, lack of spare parts and lack of technical persons. Electrical equipment's are brought far distant industrial countries, therefore they are very expensive.

The electricity supply institution (ESI) in South Sudan is characterized by:
- Main electricity supply provided from captive generation;

- Low electrification levels of less than $1 \%$ based on areas supplied by South Sudan Electricity Corporation (SSEC) with virtually no one in the rural areas having electricity; and Supply shortage, and intermittent supply of electricity within SSEC's areas of operations i.e. supply is not available through a full 24-hour period.

SSEC is operating in 3 of the 10 state capitals (Juba, Malakal and Wau) and Renk town. SSEC's distributional losses (technical and nontechnical losses) estimated at $25 \%$ (2010) were two and half times the best practice of $10 \%$ benchmark.

Moreover, SSEC's financial performance is weak with the utility's operations heavily subsidized by the government (about $75 \%$ of operational expenses are subsidized). The financial, human capacity and systems constraints in SSEC have also limited its ability to operate, maintain and expand the generation facilities and distribution networks.

\section{Present supply and demand in South Sudan:}

Table 1. Below presents the installed generation capacities in the operational areas of South Sudan Electricity Corporation (SSEC).

\begin{tabular}{|l|l|l|l|l|}
\hline \multicolumn{1}{|c|}{ Location } & $\begin{array}{l}\text { No. } \\
\text { of } \\
\text { units }\end{array}$ & $\begin{array}{l}\text { Unit } \\
\text { capacity } \\
\text { (MW) }\end{array}$ & $\begin{array}{l}\text { Total } \\
\text { Capacity } \\
\text { (MW) }\end{array}$ & Remark \\
\hline Juba (Wartsila Engine) & 8 & 1.5 & 12 & Operational \\
\hline Juba (Cummins Engine) & 5 & 1 & 5 & Not operational \\
\hline Malakal & 6 & 0.8 & 4.8 & Operational \\
\hline Wau & 2 & 1 & 2 & Operational \\
\hline Bor & 2 & 1 & 2 & $\begin{array}{l}\text { Under } \\
\text { Construction }\end{array}$ \\
\hline Yambio & 2 & 1 & 2 & $\begin{array}{l}\text { Under } \\
\text { Construction }\end{array}$ \\
\hline Rumbek & 2 & 1 & 2 & $\begin{array}{l}\text { Under } \\
\text { Construction }\end{array}$ \\
\hline Renk & 2 & \multicolumn{2}{|l|}{$\begin{array}{l}\text { Interconnection } \\
\text { with Sudan }\end{array}$} \\
\hline
\end{tabular}

Table 1: SSEC's Installed Generation Capacity

Source: Statistical year-book for Southern Sudan, 2010 and SSEC

The current demand in SSEC's supply areas is much higher than the power utility can, the assessment estimated the 2010 effective generation demand in Juba and Malakal at $32 \mathrm{MW}$ and $15 \mathrm{MW}$, respectively. The corresponding SSEC'S installed generation capacities (operational) were $12 \mathrm{MW}$ and $4.8 \mathrm{MW}$. Hence, the supply gap has forced the provide. For instance, based on 2009 SSEC surveys businesses and high class households to meet their supply deficit from own generation.

In spite of abundant sources for electricity generation (hydro and oil), the present power supply by SSEC is limited to three state capitals (Juba, Malakal and Wau) and Renk town. The state capitals are supplied from diesel power generators (installed capacity 23.8 MW), while Renk town is supplied from import from Sudan. Although 
South Sudan is interconnected with the Sudan to import 40 MVA (about $32 \mathrm{MW}$ ) of power, the import is limited to about $3 \mathrm{MW}$ (supply to Renk town) since the commercial agricultural development projects envisaged around Renk have not been realized and/or the network has not been extended to supply other major load centers. Presently, SSEC is installing $2 \mathrm{MW}$ each diesel generators and the associated distribution networks to supply three state capitals (Bor, Yambio and Rumbek), this program is funded by the Government of Egypt.

Outside SSEC supply area, the townships of Yei, Maridi and Kapoeta are supplied with electricity from USAID funded diesel power plants run by local cooperatives.

The installed capacities of the diesel generators in these towns are 1.2 MW, $0.8 \mathrm{MW}$ and $0.8 \mathrm{MW}$, respectively. The corresponding customers are 1,$100 ; 250$ and 85 . Given that the cooperatives had to recover the full cost of supply, the tariff $s$ in the towns (average tariff of 53 US cents/ $\mathrm{kWh}$ ) are more than double that of SSEC's average tariff of 22 US cents $/ \mathrm{kWh}$. The high tariffs have become constraints to connecting significant number of household customers.

Proposed development programs for improving electrical power supply in South Sudan during the upcoming period:

The challenge for the Government is therefore to implement accelerated programs to deliver sufficient, reliable and affordable supply to enhance socio-economic growth in the country. The proposed Action Plan for the power sector includes a program to address the electricity supply constraints in the short- and medium- to long-term. Given the time constraints.

Program for the Medium- Term (2016-2020) and Long-Term (20212025):

Expansion of generation capacities. The generation capacities in all the supply centers outside Juba and Malakal grids will be strengthened by installing additional diesel units (115 MW) in order to meet demands in the long-term. It is also expected that part of the mega hydropower potential (possibly Lekki $300 \mathrm{MW}$ Hydropower Plant) will be developed in the medium-term to supply the Juba Regional Grid. In the long-term, the activities to be implemented are relatively limited and involve connecting new customers, preparation of analytical studies, capacity building in the energy institutions, etc.

Expansion of the transmission network. In the medium term, it is expected that the interconnection with the neighboring countries will expand with the Ethiopia South Sudan ( $220 \mathrm{kV}$ D/S) and Uganda-South Sudan Interconnectors ( $220 \mathrm{kV} \mathrm{D/S}$ ) commissioned by the end of 2019 and 2020, respectively. The Ethiopia-South Sudan Interconnector will provide about $100 \mathrm{MW}$ to Malakal Regional Grid while the UgandaSouth Sudan Interconnector will supply about $100 \mathrm{MW}$ to Juba Regional Grid. Domestic generation combined with interconnection supply will make available relatively cheap power to the regional grids. It is expected that some of the surrounding towns will be connected to the regional grids during this period. In such event, the government could either keep the diesel generators at the existing sites to serve as a backup supply or move them to supply other unelectrified towns.

In the period 2015-2025, the generation demand will be met through:
- Imports from the Sudan

- Installation of diesel generators in the supply centers,

- Development of Fula SHP, and

- Imports from Ethiopia and Uganda.

Therefore, major transmission networks will not be developed during this period to form a meaningful national grid.

Beyond 2025, as the economy grows, it is imagined that a critical mass demand will be created to justify the formation of a national grid. The national grid will be formed through:

- The development of the hydropower resources

- Eexpansion of the national transmission networks and

- Strengthening the interconnection with the neighboring countries.

Accordingly, the north and southern part of South Sudan will be connected in 400/500 kV networks and the remaining major load centers in the country will be supplied in 220/132 kV networks. The interconnection with the neighboring countries will be strengthened through interconnecting the central part of the grid with Ethiopia and southern grid with Kenya. The 500 kV Tepi substation (Ethiopia), which will be constructed as part of the Renaissance Dam $(5,250 \mathrm{MW})$ and commissioned in the next decade, will serve as a take-off point for major interconnection (interconnection in 400/500 kV) with South Sudan. The proposed Transmission and Distribution Master Plan will determine the final shape of the national grid.

In the medium-to-long term, the distribution networks will further be developed to evacuate the power from the various substations and connect new customers.

Comparing Sudan and South Sudan Electrical power Sector:

Table 2: Sudan vs. South Sudan electrical power Sector

\begin{tabular}{|c|c|c|}
\hline & Sudan & South Sudan \\
\hline Electricity Production & $\begin{array}{l}7.193 \text { billion KWh } \\
\text { (2010 est.) }\end{array}$ & $\begin{array}{l}881.3 \text { million } \text { KWh } \\
\text { (2010 est.) }\end{array}$ \\
\hline Electricity Consumption & $\begin{array}{l}5.665 \text { billion KWh } \\
\text { (2010 est.) }\end{array}$ & $\begin{array}{l}694.1 \quad \text { million } \text { KWh } \\
\text { (2010 } \text { est.) }\end{array}$ \\
\hline Electricity Export & 0 kWh (2012 est.) & 0 kWh (2012 est.) \\
\hline Electricity Import & 0 kWh (2012 est.) & 0 kWh (2012 est.) \\
\hline $\begin{array}{l}\text { Electricity Installed } \\
\text { generation capacity }\end{array}$ & $\begin{array}{l}2.083 \text { million } \mathrm{KW} \\
\text { (2010 est.) }\end{array}$ & 255,200 kW (2010 est.) \\
\hline
\end{tabular}

Source CIA Factbook

\section{Country Comparison of electrical power Sector:}

The Global energy statistical year book of 2015 and the Central Intelligence Agency, provided the latest statistical data regarding the energy sector worldwide. All the data concerned the electricity production, consumption, consumption per capita, electricity export and import are presented below.

Map 1: Country Comparison > Electricity - production

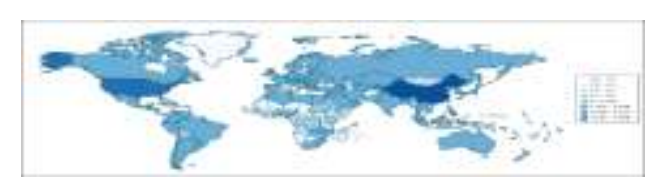


Source: CIA World Factbook

Definition of Map 1: This entry is the annual electricity generated expressed in kilowatt-hours. The difference between the amount of electricity generated and/or imported and the amount consumed and/or exported is accounted for as loss in transmission and distribution.

Description of the map: The above map shows how Electricity production varies by country, with 217 countries are covered. The shade of the country corresponds to the magnitude of the indicator. The darker the shade, the higher the value. China has the highest electricity generation with 5,398 billion (KWh), while Falkland Islands (Islas Malvinas) has the lowest electricity production. Sudan and South Sudan production of electricity is 7.19 and 0.88 respectively according to the last statistics made.

Electricity - consumption - World:

Map 2: Electricity - consumption - World

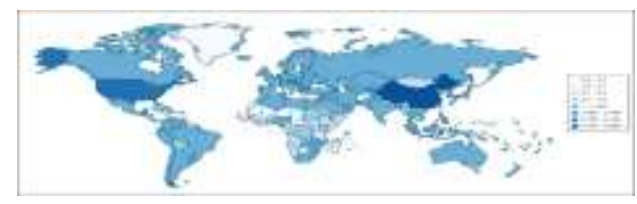

Source: CIA World Factbook

Definition of map 2: This entry consists of total electricity generated annually plus imports and minus exports, expressed in kilowatt-hours. The discrepancy between the amount of electricity generated and/or imported and the amount consumed and/or exported is accounted for as loss in transmission and distribution. Description of the map2: The above map shows how Electricity consumption varies by country. The shade of the country corresponds to the magnitude of the indicator. The darker the shade, the higher the value. However, with in 217 countries displayed in the map above, the highest consumption was found in China with 5,322 billion KWh are consumed and the lowest was in Falkland Islands (Islas Malvinas) with zero consumption. In between, the other countries varies in their consumption, while Sudan was ranked as the 109 country with 5.66 KWh consumed, and South Sudan ranked as the 158 country with 0.69 is consumed there.

\section{Electricity consumption per capita (KWh per person) - World}

Map 3: Electricity Consumption per capita

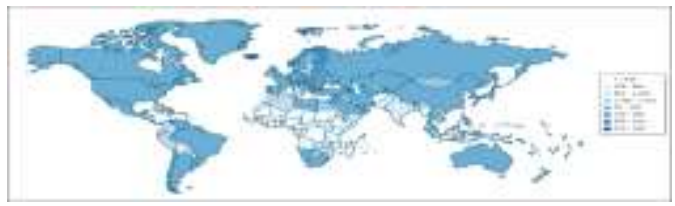

Source ClA Factbook

Description of Map 3: Iceland has the highest consumption with 51,142 KWh are consumed per person, and Chad has the lowest consumption with 8 are consumed per captia. Other countries are in between vary in their consumption, with Sudan and South Sudan consume 160 and 60.03 respectively with 217 countries are covered.

Electricity - exports - World:
Map 4: Electricity - exports - World

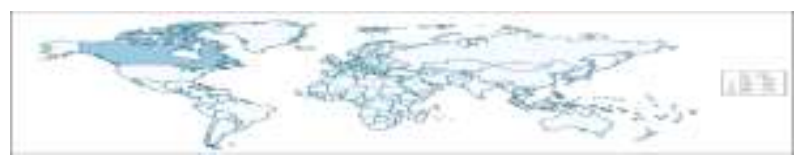

Source: CIA Factbook

Definition of the map: This entry is the total exported electricity in kilowatt-hours.

Description of map 4: The map displayed here shows how Electricity - exports varies by country. The shade of the country corresponds to the magnitude of the indicator. The darker the shade, the higher the value. Regarding the map France exceeds all countries in Export, with Sudan and South Sudan have Zero export to electricity, as still they have to strength the electrical power sector. The above map represents 217 countries, with only 91 countries export electricity and all the others have zero export as almost all the map is white.

Electricity - imports - World:

\section{Map 5: Electricity - imports - World}

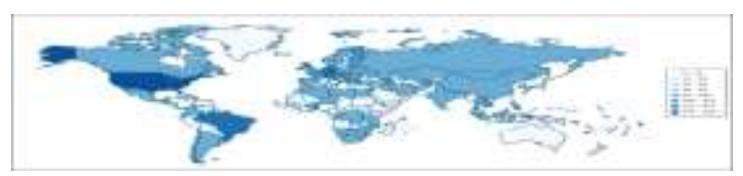

Source: CIA Factbook

Definition of map 5: This entry is the total imported electricity in kilowatt-hours.

Description of map 5: The above map shows the total imported electricity in kilowatt-hours and how Electricity - imports varies by country. The shade of the country corresponds to the magnitude of the indicator. The darker the shade, the higher the value. The United States has the highest electricity import which is 59,260 million KWh. Sudan and South Sudan has zero electricity imports.

\section{Conclusion:}

As long as electricity is available, no one thinks much about it. The importance is realized when the power goes out, whether it's during the day or at night, electricity keeps our life in order. This paper presented the electrical power sector-electricity supply in Sudan and South Sudan in terms of the different struggles faced by their citizens and various developmental plans set for improving electricity Supply in both Countries in the long run. As well as, it has compared Sudan and South Sudan electrical power sector with each other and the world.

However, South Sudan faces a very difficult situation in electricity access by citizens, so hope in the near future all the developmental plans will be implemented effectively and all people have access to electricity. On the other hand, Sudan has a better situation, as the electrical power sector is good but faces a lot of power cut offs and a lot of decisions made by government, which have an adverse effect on the citizens. Hope in the upcoming future all this problems will be solved and all the developmental plans will be implemented. 
Proc. of The Fifirth Intl. Conf. On Advances in Economics, Management and Social Study - EMS 2016

Copyright $($ Institute of Research Engineers and Doctors, USA .All rights reserved.

ISBN: 978-1-63248-089-7 doi: 10.15224/ 978-1-63248-089-7-38

\section{Acknowledgement:}

I would like to take this opportunity to thank anyone who has supported and encouraged me throughout the way. My deepest appreciation is expressed to my beloved mother for her blessings, endless support and love. My sincere gratitude to my brothers for their consistent encouragement and support.

\section{References:}

1. Amogpai ,2015, Challenges of sustainable electricity supply in South Sudan,

https://ateramogpai.wordpress.com/.../challenges-of-sustainable-

electricit

2. Country Energy Information Sudan, 2006

https:// www. Country energy information Sudan.com

3. Devex,2011,Electricity Sector Strategy Note for South Sudan, https://www.devex.com/.../electricity-sector-strategy-note-for-sout

4. Indexmundi,2014, country comparison-Thematic Map-energy sector, www.indexmundi.com/map/?v=81000

5. Jacob K. Lupai, 2012, Electric Power Availability Dreadful to the Public in Juba, https:// www. Electric power availability dreadful to the public in Juba.com

6. Jemma Nunu Kumba, Opportunities for Investors in Infrastructure by Her Excellency The Minister of Transport and/or His Excellency The Minister of Electricity and Dams and/or Her Excellency The Minister of Housing and Physical Planning, www.south Sudan, infrastructure opportunities.com

7. Lucy Electric, 2012,Case Study: The National Electricity Corporation of Sudan, www.lucyelectric.com/en/solutions/our-work/case-stu-2-2/

8. Ministry of Physical Infrastructure and Rural Development ,2014, The Project For Comprehensive Planning and Support for Urgent Development on Social Economic Infrastructure In Malakal Town, www.open_jicareport.jica.go.jp/pdf/12228953_01.pdf.com

9. Musaazi Namiti,2013, Analysis: Struggle for power in South Sudan, www.aljazeera.com/.../analysis-struggle-power-south-sudan-20

10. N Farouk, 2005, Proposal for Improve the Electrical Power Supply in Port Sudan Town., www.sersc.org/journals/IJAST/vol42/9.pdf

11. ONEC ,2013, Juba Power Distribution System Rehabilitation and Expansion Project, www.south Sudan- juba power distribution system.com

12. Mr. P. Niyimbona, 2005, Challenges of Operationalizing Power Pools in Africa https://www.Challenges+of+Operationalizing+Power+Pools+in+Africa+

13. R Morimoto and C Hope, WP 24/2001, The Impact of Electricity Supply On Economic Growth In Srilank , https://www.jbs.cam.ac.uk/.../wp0124

14. South Sudan: An Infrastructure Action Plan, 2010, Provision of Electricity and Rural Energy, www.afdb.org/...South Sudan infrastructure.com

15. Sudan Energy Market Report, 2015, www.sudan energy market report.com
16. Sudan turbine, 2015 , Sudan aspires to increase electricity production by 2020,2015 , www.sudantribune.com/spip.php?article55905

17. Sudan Turbine,2015, Sudanese government says increase in price of electricity "unavoidable, www.sudantribune.com/spip.php?article55806 The Importance of Electricity,2002, www.exampleessays.com/viewpaper/6976.html

19. The World Folio ,2015, A plan to power the country, www.theworldfolio.com/news/a-plan-to-power-the-country/3738/

20. United Nations,2014, Implementation of integrated, coherent and coordinated support to South Sudan by the United Nations system,

www.un.org/en/ecosoc/.../south_sudan_ecosoc_report.pdf

21. United Nations, 2014, South Sudan humanitarian and development statistics, www.south Sudan statistics 2014.com

22. World Bank, Sudan: Electricity consumption per capita $(\mathrm{kWh})$, http://www.factfish.com/statistic-

country/sudan/electricity+consumption+per+capita

About Author (s):

Miss. Dina Ahmed Mohamed Ghandour, is a full time
lecturer at University of Medical Sciences and
Technology, Faculty of Business Administration. She
prepared her BSc. and Master's degree at the field of
Business Administration; finance specialization, and
wrote number of research papers which has been
published in various international journals. Miss
Ghandour also attended and participated in different
International Conferences.

